\title{
EPIDEMIOLOGICAL AND GEOGRAPHIC FACTORS IN DIABETES
}

\author{
D. R. R. WILLIAMS \\ Cambridge
}

\begin{abstract}
SUMMARY
Both non-insulin-dependent (type 2) diabetes mellitus (NIDDM) and insulin-dependent (type 1) diabetes mellitus (IDDM) show a wide variation in incidence and prevalence in different populations. The prevalence of NIDDM varies from close to zero in some populations to $40-50 \%$ in the adults of Nauru (Pacific) and in the Pima Indians (North America). The incidence of IDDM in children under 16 years ranges from around 30/100 000 children per year in Finland and other Northern European countries to less than 1/100 000 per year in Japanese children. Many genetic and environmental factors combine to produce this variation. Among the suggestions made for NIDDM are the 'thrifty genotype' and, more recently, the 'thrifty phenotype' hypotheses of Neel and of Hales and Barker respectively. Genetic and environmental factors in IDDM in children have combined to create an apparent gradient of decreasing incidence from northern to southern European countries but with at least one local 'hot spot': the island of Sardinia. The factors responsible for this pattern, and the increasing incidence over time, require further clarification.
\end{abstract}

This paper deals with selected aspects of the descriptive epidemiology of diabetes. It will take as its starting point the usual concerns of descriptive epidemiology: those of person, place and time. It will document some of what is known about the characteristics of the people who get diabetes, how this varies according to geographical location; it will also describe how the incidence of diabetes is changing with time and how it varies with the season of the year. It will contain a mixture of recent observations and some which have become classics in the literature.

It is probably usual in summaries of this sort to begin with insulin-dependent (type 1) diabetes mellitus (IDDM) and then to proceed to non-insulin-dependent (type 2) diabetes mellitus (NIDDM). This account will do the

Correspondence to: Dr. Rhys Williams, Department of Community Medicine, Institute of Public Health, University Forvie Site, Robinson Way, Cambridge CB2 2SR, UK. reverse. This is principally to emphasise that, on a worldwide basis, NIDDM and its complications make by far the larger impact on the health of the public in terms of morbidity, mortality and the use of health services. IDDM and its complications have a greater impact in terms of years of life lost and it could be debated which of the two major manifestations of the diabetic state has the greater impact on quality of life; however, in terms of the more widely used measures of public health impact, NIDDM is by far the more important of the two.

\section{NON-INSULIN-DEPENDENT DIABETES MELLITUS}

When information on the prevalence of diabetes in different populations is compared, it is apparent that a wide variation exists. King ${ }^{1}$ has collated prevalence estimates derived from studies which have used WHO criteria for the detection and definition of diabetes ${ }^{2}$ and all of which fulfil certain rigorous standards of population sampling, biochemical analysis and so on. Prevalence estimates (of diabetes in adults) in this series range from less than $1 \%$ for the rural and urbanised Bantu to between $40 \%$ and $50 \%$ for the indigenous population of Nauru and the Pima Indians.

Although these data are used here as an illustration of the enormous range of prevalences of NIDDM in different populations, they are, strictly speaking, estimates of the total prevalence of all forms of diabetes combined. For most of the populations concerned, however, NIDDM comprises the bulk of the cases already diagnosed and newly detected in population surveys.

As an explanation of the extraordinarily high prevalances in these now quite famous populations (Nauruans and Pimas, for example), the American geneticist $\mathrm{Neel}^{3}$ put forward the 'thrifty genotype' hypothesis. This suggested that selective pressures over many successive generations of a 'feast and famine' hunter-gatherer existence resulted in a high prevalence of a genotype conferring a selective advantage on individuals leading that existence but which predisposed to the later emergence of diabetes 
in these populations after an abrupt change to a relatively sedentary urban lifestyle with a high intake of refined carbohydrate, fat and alcohol.

My own experience of working with these high prevalence populations is with the urbanised Australian aboriginal populations of New South Wales. ${ }^{4.5}$ Their prevalences of diabetes, obesity, hypertension and ischaemic heart disease are currently very high (though not, on the whole, well documented). As far as is known, the aboriginal peoples of Australia did not suffer from these diseases in their former, non-urbanised existence and these changes in disease frequencies have gone hand in hand with the widespread disintegration of the structure and organisation of their society.

Dowse $^{6}$ and his colleagues in Australia have put forward the idea that consideration of the ratio of impaired glucose tolerance (IGT) to total glucose impairment (TGI) (i.e. IGT + NIDDM) and the current prevalence of NIDDM in various populations can give an indication of the current position of any given population on the 'epidemic curve' of NIDDM.

Some populations, like those of rural Papua New Guinea, have a high IGT/TGI ratio with a low prevalence of diabetes. This has been interpreted by Dowse et al. to suggest that they are in the early stages of an NIDDM epidemic with a comparatively high proportion of individuals in the early stages of the disease process and comparatively few with frank diabetes. In contrast, Nauruan and Australian aboriginal populations have comparatively low values of the IGT/TGI ratio and high prevalences of diabetes, suggesting a more advanced position along the epidemic curve.

Adult obesity is strongly associated with NIDDM both on an individual basis and in populations. The well-known international comparison by West and Kalbfleisch ${ }^{7}$ demonstrated a close positive correlation between the prevalence of diabetes in the 10 populations considered and their chosen measure of obesity (mean 'percentage standard weight'). Since then this relationship has been amply confirmed.

It is not only the characteristics of adult body size and shape, however, that seem to be important in determining the risk for developing NIDDM in adults. Recently, Hales and Barker and their colleagues ${ }^{8}$ have described an association between birth weight and weight at 1 year (both measured over 60 years ago) and the development of IGT and diabetes in later adult life. Their observations were made possible by the meticulous recording of these data by a midwives working in the 1920s and 1930s and their ability to trace a substantial number of the survivors of this cohort and subject them to oral glucose tolerance tests (OGTTs) in adult life. The OGTT data they obtained showed higher prevalences of both IGT and NIDDM in the lighter birth weight (and lighter weight-at-1-year) groups than in the heavier, with odds ratios of 6.6, 4.8, 4.6, 2.6, 1.4 and 1.0 (for IGT and NIDDM taken together) from the lightest $(\leqslant 2495 \mathrm{~g})$ to the heaviest $(>4309 \mathrm{~g})$ birth weight groups. ${ }^{8}$
Their conclusions from this work are that relative malnutrition in fetal and early life confer a risk for the development of IGT and NIDDM in adult life and that this may operate through the presence of a lower beta cell mass in adults who survived these conditions in early life. They further speculate that this is an adaptive response of the fetus and infant to poor nutrition - a response which becomes maladaptive (in that it leads to IGT and NIDDM) in adult life, especially when the individual is subject to the metabolic stresses of obesity. They have termed this the 'thrifty phenotype'. ' This suggestion, if true, does not necessarily have to be regarded as a competitor to the thrifty genotype of Neel but could produce its effect in combination with it in some populations under certain circumstances.

\section{INSULIN-DEPENDENT DIABETES . MELLITUS}

One of the most important advances in IDDM epidemiology has been the establishment of complete, populationbased registers of IDDM in childhood. A recent summary of the information derived from such registers ${ }^{10}$ has highlighted the differences in incidence of IDDM in children living in the countries of northern Europe (Finland, Sweden and Scotland) and those living in Japan. Incidence in Finnish children is around 30/100 000 per year (in children under 16) and less than 1/100 000 per year in Japanese children. These data also suggest a decline in incidence between the north and south of Europe, although this effect is less clear in North America.

A recent observation which has called into question the idea of a simple north-south gradient is that of Gale and his colleagues. ${ }^{11}$ They have observed (as part of the EC funded 'Eurodiab' programme) that the incidence of IDDM in Sardinia is as high as that recorded in Finland and very different to that seen in equally comprehensive childhood diabetes registers in the Italian mainland (see Table I). The reasons for this 'hot spot' in Sardinia and, indeed, the reasons for the generally higher incidences among children living in northern European countries compared with those living in southern European countries, are not entirely clear. The population frequencies of the various genetic markers that have been implicated in IDDM can explain part but not all of this pattern. The facts that Finnish children and Estonian children (who share cultural, linguistic and genetic characteristics) have very different incidence rates of diabetes ${ }^{12}$ and that the incidence of diabetes in northern European countries is increasing rapidly ${ }^{13}$ both contribute to the view that environmental factors, as well as genetic factors, are necessary for the development of the disease in European children.

Another epidemiological observation which is relevant here is that the onset of IDDM shows seasonal variation, with higher rates in autumn and winter than in spring and summer. This observation, confirmed recently by many diabetes registers throughout the world in both northern and southern hemispheres, was originally made by 
Table I. Age-specific and sex-specific incidence rates of insulindependent diabetes mellitus in Sardinia compared with other European populations ${ }^{11}$

\begin{tabular}{|c|c|c|c|c|c|c|}
\hline \multirow[t]{3}{*}{ Country } & \multicolumn{6}{|c|}{ No. of cases per 100000 per year } \\
\hline & \multicolumn{3}{|c|}{ Boys (yr) } & \multicolumn{3}{|c|}{ Girls (yr) } \\
\hline & $0-4$ & $5-9$ & $10-14$ & $0-4$ & $5-9$ & $10-14$ \\
\hline $\begin{array}{l}\text { Finland } \\
\text { ( } 2 \text { regions })\end{array}$ & 27.8 & 48.4 & 64.7 & 27.2 & 31.5 & 59.4 \\
\hline $\begin{array}{l}\text { Italy } \\
\text { (Lombardia region) }\end{array}$ & 4.8 & 9.7 & 8.4 & 4.8 & 5.3 & 7.6 \\
\hline $\begin{array}{l}\text { Italy } \\
\text { (Sardinia) }\end{array}$ & 23.4 & 40.1 & 36.9 & 19.6 & 32.0 & 29.1 \\
\hline $\begin{array}{l}\text { United Kingdom } \\
\text { (Oxford region) }\end{array}$ & 15.2 & 14.3 & 23.9 & 11.3 & 13.4 & 20.0 \\
\hline
\end{tabular}

Adams ${ }^{14}$ who plotted the months of onset of 317 consecutive cases of what he called 'acute diabetes'. He commented that more of those cases presented during the autumn and winter months than during the spring and summer. In fact, when his data are subjected to statistical analysis (by means of the chi-squared 'one-sample' test, which had not been introduced at the time Adams' research was carried out) the difference is not statistically significant. His observation was correct, however, though it was ignored until the early 1970s when populationbased registers began to produce information on month of onset.

\section{CONCLUSION}

Thus, from a combination of recent and long-established observations an understanding of some of the person, place and time characteristics of diabetes can be obtained. The observations of descriptive epidemiology are, in essence, simple. However, to produce valid information in this way is exacting and demands population-based registers and studies carried out with care and rigour.

Key words: Diabetes mellitus, Epidemiology, Geographic factors, IDDM, NIDDM.

\section{REFERENCES}

1. Ahren B et al. Global estimates for prevalence of diabetes mellitus and impaired glucose tolerance in adults. Diabetes Care (in press).

2. WHO Study Group. Diabetes mellitus. Geneva: World Health Organization, 1985. Technical Report Series 727.

3. Neel JV. Diabetes mellitus: a 'thrifty' genotype rendered detrimental by 'progress'? Am J Hum Genet 1962;14: 353-62.

4. Cameron WI, Moffitt PS, Williams DRR. Diabetes mellitus in the Australian Aborigines of Bourke, New South Wales. Diabetes Res Clin Pract 1986;2:307-14.

5. Williams DRR, Moffitt PS, Fisher JS, Bashir HV. Diabetes and glucose tolerance in the New South Wales coastal Aborigines: possible effects of non-Aboriginal genetic admixture. Diabetologia 1987;30:72-7.

6. Dowse GK, Zimmet PZ, King H. Relationship between prevalence of IGT and NIDDM in a population. Diabetes Care 1991;14:968-74.

7. West KM, Kalbfleisch JM. Influence of nutritional factors on prevalence of diabetes in ten countries. Diabetes 1971; 20:99-108.

8. Hales CN, Barker DJP, Clark PMS, Cox LJ, Fall C, Osmond C, Winter PD. Fetal and infant growth and impaired glucose tolerance at age 64. BMJ 1991;303:1019-22.

9. Hales CN, Barker DJP. Type 2 (non-insulin-dependent) diabetes mellitus: the thrifty phenotype. Diabetologia 1992; 35:595-601.

10. Rewers M, LaPorte RE, King H, Tuomilheto J. Trends in the prevalence and incidence of diabetes: insulin-dependent diabetes mellitus in childhood. Worlds Health Stat Q 1988; 41:179-89.

11. Green A, Gale EAM, Patterson CC. Incidence of childhoodonset insulin-dependent diabetes mellitus: the Eurodiab ACE study. Lancet 1992;339:905-9.

12. Kalits MA, Podar T. Incidence and prevalence of type 1 (insulin-dependent) diabetes in Estonia in 1988. Diabetologia 1990;33:346-9.

13. Bingley PJ, Gale EAM. The rising incidence of insulin dependent diabetes in Europe. Diabetes Care 1989;12: 289-95.

14. Adams SF. The seasonal variation in the onset of acute diabetes. Arch Intern Med 1926;37:861-4. 